6 - ORIGINAL ARTICLE

MODELS, BIOLOGICAL

\title{
Experimental models of renal dysfunction in female rats. Functional and histological aspects after unilateral nephrectomy or ligation of right renal vein with kidney preservation $^{1}$
}

\author{
Ingrid Anita Colombo Wadih Schumann Racanicchi', Ana Beatriz Soares de Oliveira', Renato Lamounier Barbieri' ${ }^{\mathrm{II}}$, Humberto \\ Dellế $^{\mathrm{II}}$, Ivone da Silva Duarte ${ }^{\mathrm{IV}}$, Pedro Luiz Squilacci Leme ${ }^{\mathrm{v}}$ \\ DOI: http://dx.doi.org/10.1590/S0102-865020150120000006 \\ IGraduate student, Universidade Nove de Julho (UNINOVE), Sao Paulo-SP, Brazil. Technical procedures, acquisition of data. \\ IIPhD, Laboratory of Experimental Research on Histology, UNINOVE, Sao Paulo-SP, Brazil. Scientific and intellectual content of the study, \\ histopathological examinations. \\ ${ }^{\text {III } P h D, ~ L a b o r a t o r y ~ o f ~ E x p e r i m e n t a l ~ R e s e a r c h ~ o n ~ P h y s i o l o g y, ~ U N I N O V E, ~ S a o ~ P a u l o-S P, ~ B r a z i l . ~ S c i e n t i f i c ~ a n d ~ i n t e l l e c t u a l ~ c o n t e n t ~ o f ~ t h e ~ s t u d y . ~}$ \\ ${ }^{\mathrm{IV}} \mathrm{PhD}$, Laboratory of Experimental Research on Surgery, UNINOVE, Sao Paulo-SP, Brazil. Scientific and intellectual content of the study. \\ ${ }^{\mathrm{v}} \mathrm{PhD}$, Laboratory of Experimental Research on Surgery, UNINOVE, Sao Paulo-SP, Brazil. Conception and design of the study, manuscript writing.
}

\section{ABSTRACT}

PURPOSE: To compare renal dysfunction after right nephrectomy and ligation of the right renal vein with preservation of kidney.

METHODS: Animals' weight, pH, density, protein in urine and histological samples of the kidneys were evaluated. Fifteen female rats (Wistar) were divided into three groups. In the control group, right renal vein dissections were performed. In the second group, the right nephrectomy was performed. In the third group, the right renal vein was ligated and the kidney was preserved. Urine samples were taken before, three and seven days after the procedure. On the seventh postoperative day the kidneys were removed to histopathological study. Analysis by Student's t test was performed.

RESULTS: weight loss, alterations of urine $\mathrm{pH}(\mathrm{p}<0.05)$, in specific gravity, proteinuria $(\mathrm{p}<0.05)$ were found in groups 2 and 3 ; hemorrhagic infarction and edema were found after ligation of the right renal vein; changes in the left kidney were also observed on the seventh day.

CONCLUSIONS: Unilateral nephrectomy and ligation of the right renal vein produced early changes in glomerular filtration, being more intense in group 3. The contralateral kidney preserved failed to properly maintain renal function in both situations.

Key words: Kidney/physiopathology. Acute Kidney Injury/pathology. Proteinuria. Renal Veins. Models, Animal. Rats. 


\section{Introduction}

Several experimental models have been developed for the study of renal physiology ${ }^{1-4}$. The models based on partial obstruction of arterial blood flow are used to evaluate renovascular hypertension. For the study of renopriva hypertension, reduction of functional renal tissue may be used, obtained either by bilateral nephrectomy and increased intake of sodium chloride, or by the removal of one kidney and two thirds of the contralateral kidney, since the unilateral nephrectomy causes neither hypertension nor cardiovascular lesions in mice ${ }^{5,6}$.

Venous ligatures are currently most used for studies on thrombogenesis ${ }^{7-10}$ and not to evaluate parameters of renal dysfunction on short term. In the 1950s and 1960s renowned experimental studies on the obstruction of the renal vein in dogs and mice, as well as its effects on renal function and histology were performed ${ }^{11}$, showing early alterations in both situations, represented by significant proteinuria, hemorrhagic infarction and congestion the renal parenchyma. Some changes would be reversed with the development of collateral circulation, especially when the renal veins were ligated near the inferior vena cava and the blood draining to the left gonadal vein, or other tributaries of the renal vein, allowing early functional recovery.

Threefoot et al. ${ }^{11}$ made plastic models with the injection of methacrylate in the arteries and veins and corrosion of tissues to assess the effectiveness of venous ligatures, confirming the early development (between one and three days), of collateral circulation for kidneys' drainage. The histological findings of these authors, when the right kidney was assessed, between the first and fifteenth day, were mostly infarction, bleeding and hemorrhagic necrosis. Sixty to eighty percent of animals, on the first and second days, developed edema and congestion, as well as degeneration of the tubules. Between the seventh and the ninth day, also considering the right kidney, the authors found the same infarction with hemorrhage and hemorrhagic necrosis in all animals, as well as edema and congestion, signs of infection with leukocyte infiltration, degeneration of tubules, interstitial fibrosis and thinning of basal membrane in fifty to seventy-five percent of the studied kidneys. Proteinuria found by the authors showed a peak around the second day after ligation and it was near the baseline values by the fifth day after surgery, both in animals that had hematuria and those without.

The aim of this study was to compare the changes that follow the right nephrectomy or ligation of the right renal vein with preservation of kidney, evaluating urinary parameters and histological aspects related to renal function of animals.

\section{Methods}

This study was carried out at the Advanced Surgical Skills Laboratory, Universidade Nove de Julho, in accordance with the Federal Law 11.794 of October 2008, regulated by Decree 6.689 of July 2009, after being authorized by the Ethics Committee on Animal Use (protocol 0042/2012). Care with the preparation of the animals, anesthesia, postoperative analgesia are always strictly supervised at the Institution and follow specific protocols ${ }^{12,13}$.

A total of 15 animals (Rattus Norvegicus, var. Albinus, Rodentia Mammalia), Wistar strain, female, weighing between $260 \mathrm{~g}$ and $380 \mathrm{~g}$ were divided into three groups of five animals each, classified according to type of surgery. In group 1 (shamoperated), the right renal vein was just dissected. This option was chosen for being an easier technique in rats, since the ovarian vein is a tributary of the inferior vena cava and not of the renal vein as it occurs in the left, which reduces the appearance of early collateral circulation $^{11}$. In group 2, right nephrectomy was performed and, in the third group, the right renal vein was occluded with 6-0 nylon suture nearby the renal hilum, preserving the ureter and the renal artery. The fifteen rats were reoperated after seven days, since the life cycle of the rat allows the observation of early alterations ${ }^{14}$ (Figure 1).

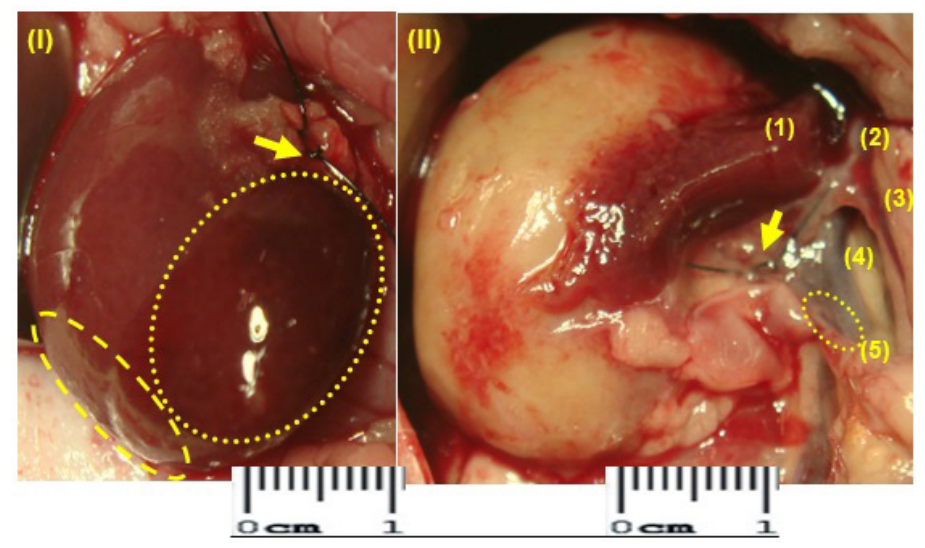

FIGURE 1 - (I) Ligation of the right renal vein (arrow) nearby the hilum in the first operation of group 3, resulting in early areas of congestion and infarction (highlights). (II) The same kidney after one week: (1) hepatic fragment adhered to the kidney, (2) portal vein, (3) superior mesenteric vein, (4) inferior vena cava, (5) right ovarian vein. The arrow shows the ligation performed in the renal vein. Extensive lesion of the parenchyma with no evidence of collateral circulation. Signs of arterial blood perfusion, suggesting integrity of the renal artery flow. 
Before and after completion of surgical procedures, the rats remained in individual cages with access to water and standard chow ad libitum, maintained at a temperature of $25^{\circ} \mathrm{C}$, cycles of light and dark each twelve hours. Urine was collected with the aid of individual metabolic cage for evaluation of $\mathrm{pH}$, density, and presence of proteins. The rats were weighed, anesthetized with intraperitoneal injection of ketamine $(50 \mathrm{mg} /$ $\mathrm{kg})$ and xylazine $(10 \mathrm{mg} / \mathrm{kg})$ and underwent a midline laparotomy. After all procedures proposed for each of the three groups, the operation was completed with suture of anterior abdominal wall in layers with 4-0 nylon thread.

The rats were kept in the vivarium for seven days, being the urine of the third day after the first operation as well as the urine collected before the beginning of the second surgical procedure, taken for comparison. Seven days later the animals were weighed, anesthetized again and reoperated in order to evaluate the macroscopic changes of the abdominal organs; the kidneys were removed for histological examination, being preserved in a $10 \%$ formaldehyde solution for 24 hours, then dehydrated in progressive ethylic alcohol concentration, diaphanized with xylol and embedded in paraffin. Serial cuts of 5 microns stained with hematoxylin and eosin were performed. Glass slides were photographed with the aid of an optical microscope with 40x lens, 0.65 numerical aperture and eyepiece of $5 \mathrm{x}$, producing an increase of 200 times, corrected for lens aberrations with cover glass of $0.17 \mathrm{~mm}$, which provided a detailed resolution of 0.5 micrometers.

In order to analyze urine samples, reactive tapes for diagnosis (Urine Strip $10^{\circledR}$ Wiener lab ${ }^{\mathrm{TM}}$ ) were used; strips with reagents were placed in contact with the urine for about one second and the results were evaluated between 60 and 90 seconds, procedure always performed by the same observer. Data were statistically analyzed by Student's t test.

\section{Results}

The five animals in the control group slightly increased the weight after a week, ranging in average from $298 \mathrm{~g}$ to $300 \mathrm{~g}$. Animals in group 2 (right nephrectomy), decreased from $302 \mathrm{~g}$ to $287 \mathrm{~g}$, a decrease around $15 \mathrm{~g}(-4.96 \%)$. The ones in group 3 (ligation of the right renal vein), weighed around $301 \mathrm{~g}$ and ended with $272.4 \mathrm{~g}$, a decrease of $28.6 \mathrm{~g}(-9.5 \%)$, values that were not statistically significant (Table 1).
TABLE 1 - Variations referring to the mean in the weight (g) of animals.

\begin{tabular}{cccc}
\hline Animal weight mean (g) & $\begin{array}{c}\text { Group 1 } \\
\text { (control) }\end{array}$ & $\begin{array}{c}\text { Group 2 } \\
\text { (right nephrectomy) }\end{array}$ & $\begin{array}{c}\text { Group 3 } \\
\text { (renal vein ligation) }\end{array}$ \\
\hline Preoperative values & 298 & 302 & 301 \\
Postoperative values & 300 & 287 & 272,4 \\
Mean variation $(\mathrm{g})$ & +2 & -15 & $-28,6$ \\
Mean variation $(\%)$ & $+0,6$ & $-4,96$ & $-9,5$ \\
Statistical significance $(\mathrm{p}<0.05)$ & NS & NS & NS \\
\hline
\end{tabular}

NS: not significant

The $\mathrm{pH}$ of the first urine assessed in the three groups of animals ranged between 5 and 8 (mean 6.5) even with the animals being kept under similar conditions without water restriction. After the operations there were no changes in the results of group 1 (control), which showed similar $\mathrm{pH}$, between 6.2 and 6.5 , but in both, group 2 (right nephrectomy) and group 3 (renal vein ligation), there was a pH increase between 8 and 9 on the third and seventh days, a mean of 8.4 in group 2 and 8.8 in group 3 (Table 2 ). The $\mathrm{pH}$ values found in the postoperative period were very close in the latter two groups, not statistically significant but, when the initial $\mathrm{pH}$ was assessed in relation to the postoperative period, statistical significance was observed $(p<0.05)$.

The specific gravity of urine, which ranged between 1017 and 1019 preoperatively, decreased to 1011 and 1010 for group 2 and group 3. The values of proteins found in urine, which varied between 15 and $18 \mathrm{mg} / \mathrm{dl}$ before the operation increased to 260 $\mathrm{mg} / \mathrm{dl}$ (about 16 times higher than the control) in group 2 and 440 $\mathrm{mg} / \mathrm{dl}$ (about 26 times higher) in group 3; these values also showed statistical significance $(\mathrm{p}<0.05)$ - (Table 2$)$.

TABLE 2 - Variations referring to the mean of $\mathrm{pH}$, specific gravity and protein concentration $(\mathrm{mg} / \mathrm{dl})$ in the urine of the three groups of animals.

\begin{tabular}{|c|c|c|c|}
\hline urine $\mathrm{pH}$ (mean) & $\begin{array}{l}\text { Group } 1 \\
\text { (control) }\end{array}$ & $\begin{array}{c}\text { Group } 2 \\
\text { (right nephrectomy) }\end{array}$ & $\begin{array}{c}\text { Group } 3 \\
\text { (renal vein ligation) }\end{array}$ \\
\hline Preoperative values & 6,3 & 6,2 & 6,5 \\
\hline Postoperative values & 6,4 & 8,4 & 8,8 \\
\hline Mean variation & $+0,1$ & $+2,2$ & $+2,3$ \\
\hline Statistical significance $(p<0.05)$ & NS & $\mathbf{s}$ & $\mathrm{s}$ \\
\hline Urine specific density (mean) & $\begin{array}{l}\text { Group } 1 \\
\text { (control) }\end{array}$ & $\begin{array}{c}\text { Group } 2 \\
\text { (right nephrectomy) }\end{array}$ & $\begin{array}{c}\text { Group } 3 \\
\text { (renal vein ligation) }\end{array}$ \\
\hline Preoperative values & 1017 & 1017 & 1019 \\
\hline Postoperative values & 1018 & 1011 & 1010 \\
\hline Mean variation & +1 & -6 & -9 \\
\hline Statistical significance $(\mathrm{p}<0.05)$ & NS & NS & NS \\
\hline
\end{tabular}




\begin{tabular}{cccc}
\hline $\begin{array}{c}\text { Proteins in urine (mean) } \\
\mathbf{m g} / \text { dl }\end{array}$ & $\begin{array}{c}\text { Group 1 } \\
\text { (control) }\end{array}$ & $\begin{array}{c}\text { Group 2 } \\
\text { (right nephrectomy) }\end{array}$ & $\begin{array}{c}\text { Group 3 } \\
\text { (renal vein ligation) }\end{array}$ \\
\cline { 2 - 4 } Preoperative values & 15 & 18 & 15 \\
Postoperative values & 15 & 260 & 440 \\
Mean variation & - & +242 & +425 \\
Statistical significance $(\mathrm{p}<0.05)$ & NS & $\mathrm{S}$ & $\mathrm{S}$ \\
\hline
\end{tabular}

NS: not significant. S: significant

The macroscopic appearance of the remaining left kidney in groups 2 and 3, which has not been handled in the first operative procedure, did not suggest major changes seven days after the experiment although, in the histological study, erythrocytes were observed within the tubules (Figure 2).

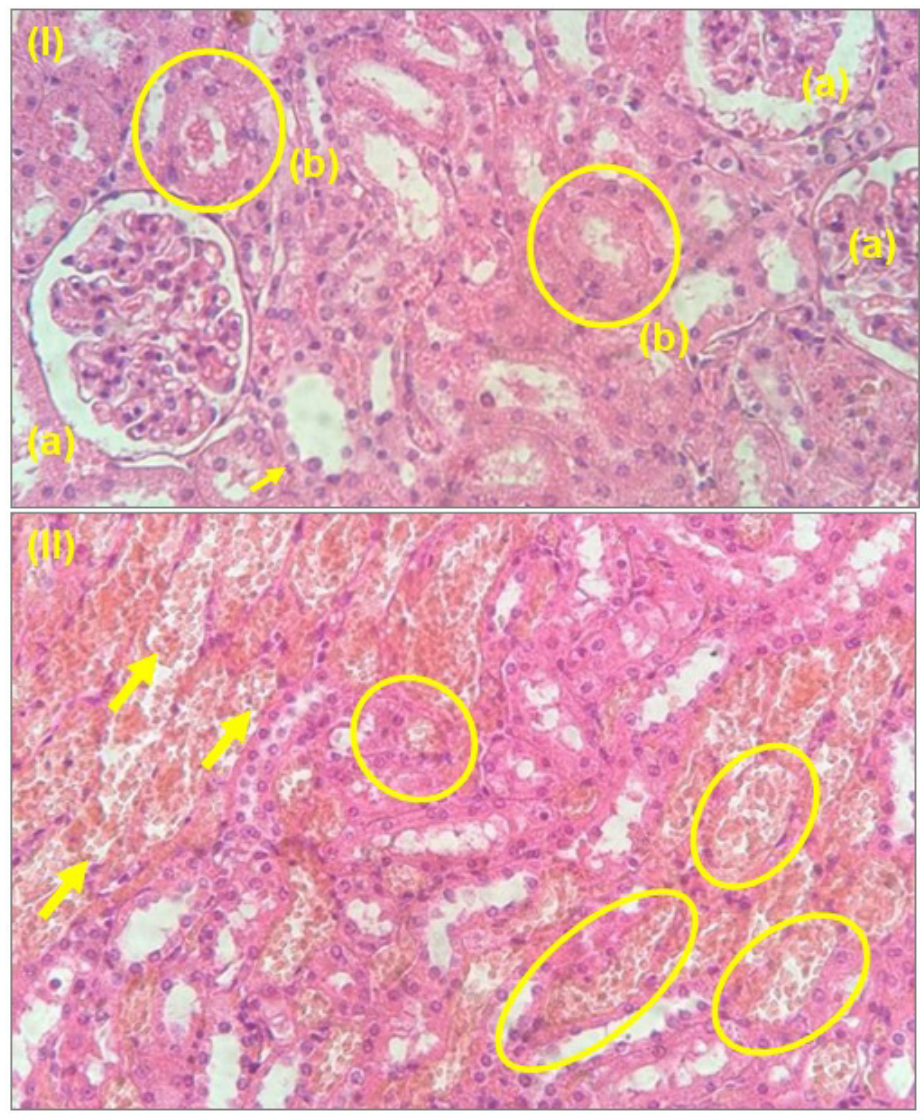

FIGURE 2 - Histological aspects of the left kidney (unhandled) with 200x magnification, on the seventh postoperative day ligation of the right renal vein. (I) Cortical region: renal corpuscles (a), proximal tubules congested (b) and distal tubule (arrow). (II) Medullary region: red blood cells within the collecting tubules (highlights) and some Henle's loops (block arrows).

In the five animals of group 3, extensive renal infarction and areas suggesting arterial perfusion, demonstrating the integrity of the arterial blood flow, can be macroscopically noticed (Figure 1). The microscopic aspect of the kidney confirmed hemorrhage, structural changes, edema and intra-renal thrombosis (Figures 3 and 4).

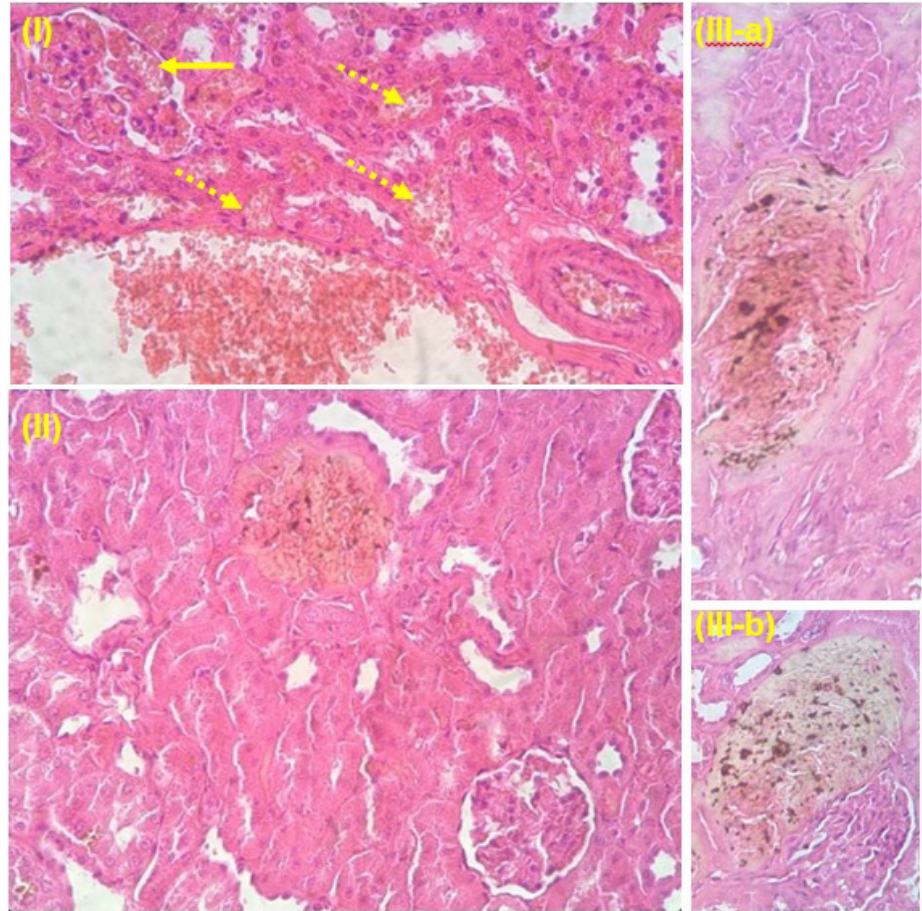

FIGURE 3 - Histological aspects of the right kidney cortical region, with 200x magnification, on the seventh day after ligation of the right renal vein. (I) Presence of red blood cells in convoluted tubules (dashed arrows) and changes in glomerular morphology (arrow). (II) Swollen tubules, showing alteration of renal architecture and thrombosis. III-a and III-b: intrarenal thrombus under organization.

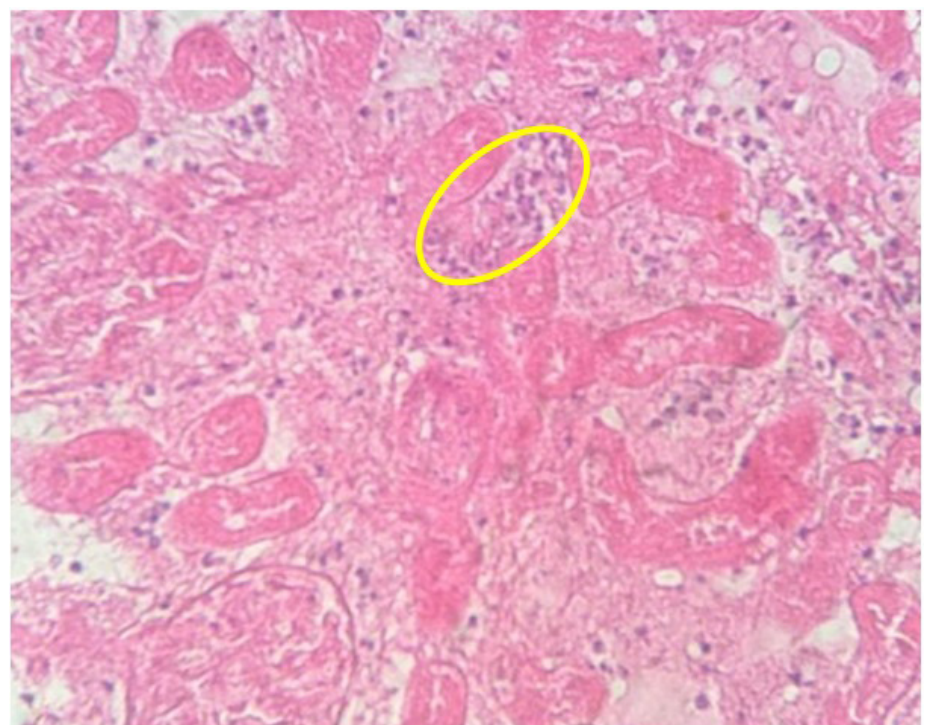

FIGURE 4 - Histological aspects of the right kidney, with x200 magnification, on the seventh day after ligation of the right renal vein. Cortical region showing alteration of tubular architecture, generalized inflammation, and polymorphonuclear infiltrate (highlighted).

\section{Discussion}

The membrane of renal capillaries is porous to water and to other elements dissolved in the plasma and shows low permeability to proteins $s^{2,15}$. Proteinuria is a marker of kidney disease and a risk 
factor for progression, as well as of cardiovascular diseases, being a prognosis factor ${ }^{2,16,17}$. In humans and experimental animals, the operations performed in the abdomen, even without manipulation of the kidney or renal vessels, are accompanied by transient proteinuria ${ }^{11}$, but at least two thirds of each kidney must be injured until clinical signs are evident. In the experiment carried out, the reduction of functioning renal parenchyma induced by right nephrectomy or by renal infarction caused by ligation of the renal vein produced severe proteinuria, indicating some alterations in the permeability of the glomerular membrane, regardless of the left kidney preservation. Ligation of the right renal vein near the hilum induced renal infarction even with the preserved artery.

The nephron regulates the glomerular filtrate so that end products of metabolism are eliminated ${ }^{6,18-20}$ and about seventyfive percent of water, electrolytes, glucose, several amino acids and proteins of this filtrate are reabsorbed in the proximal tubules. The remaining volume goes through the Henle's loop, distal and collecting tubules where variable amounts of water and electrolytes are reabsorbed, depending on the needs of the organism, causing a great variation of the osmotic pressure of the tubular fluid. In the experimental models described here urine was diluted, with reduction of its specific gravity, implying loss of tubular function and inability to reabsorb water, suggesting that in these animals the unique kidney failed to have adequate vicarious function.

The ion transporters by renal cells have been extensively studied with the new resources of molecular biology and are essential for the evaluation of drugs and treatments for some kidney diseases ${ }^{1,4,6,18-21}$. Lines of research related to renal endocrine function can also be developed based on experimental models where renal vein is ligated, which would prevent substances such as erythropoietin, vitamin $\mathrm{D}$ metabolites or even renin released by the kidney, from reaching the systemic circulation. Murine models are useful for short-term studies, since rats and mice have high metabolic rates and events occur rapidly ${ }^{14}$. In this study we evaluated the presence of protein, $\mathrm{pH}$ and density of the animals' urine before the first operation, three days later and seven days after the three performed procedures. The evaluation of urine on the third day after the initial operation was able to confirm that early changes occur. Similar values were obtained on the seventh day. Urine is normally slightly acidic and contains low concentrations of protein. The urine $\mathrm{pH}$ increased, suggesting impaired ability to regulate the concentrations of hydrogen ions and bicarbonate. The animals lost weight in both situations assessed and, as protein loss as the inability to concentrate urine, may have contributed to these results.
Classic studies ${ }^{11}$ showed hematuria especially afterligation of both renal veins and, when this occurred, higher proteinuria was observed, possibly resulting from venous congestion. When the unilateral ligation of the renal vein was performed, hematuria was seen in almost a quarter of the animals on the third day and in less than five per cent on the seventh day after the procedure. Acute inflammation of the glomeruli is followed by edema, reduction of glomerular blood flow and its membrane lesion allowing passage of red blood cells and proteins to the tubule ${ }^{6}$. Although this finding was expected and histologically erythrocytes in the renal tubules were observed, the analysis of urine in this study looking for hematuria, did not confirm such finding, both on the third and on the seventh day after the experiment. Significant proteinuria and infiltration of polymorphonuclear cells were found (Figure 4).

Most experimental models of hypertension make use of renal hypoperfusion, either by constriction of the aorta or renal arteries, with no reference to the renal vein ${ }^{2,5,22-24}$, but hypertension after renal vein thrombosis clinically can occur ${ }^{8,22}$. The dissection of the renal artery of the rat is laborious, but both nephrectomy and the ligation of the renal vein are easily performed, as well as the veins in murine models are more suitable for training ${ }^{10}$. Although human right renal vein is smaller and close to the inferior vena cava, the right kidney in rats is more mobile and easier to dissect, as well as the right ovarian vein in the studied rats was a direct tributary of the inferior vena cava (Figure 1-II). Collateral circulation in the renal hilum was not observed at the end of the study in any of the animals studied. The choice for the ligation of right renal vein, besides technical facility, was due to the anatomical detail of left ovarian vein which is a tributary of the left renal vein and not of inferior vena cava as it occurs to the right, reducing the chance of collateral circulation, which would be set in early. The ligation of the left renal vein near the vena cava allows blood drainage of the kidney by the gonadal vein interfering in the results ${ }^{11}$.

Evans et $a .^{25}$ reported the occurrence of congenital unilateral renal vein thrombosis, followed by hypertension and dilution of the urine of the neonate that presented values of specific gravity between 1000 and 1002, weight loss and hemoconcentration, but no change in urea and electrolytes. In the polyuric phase there was a decrease in potassium levels and increased renin, parameters that have been corrected with the removal of the affected kidney in the seventh week of life. The renal vein thrombosis is more usual in the neonatal period ${ }^{26}$ and it is accompanied by hypertension, proteinuria and renal failure $9,15,17,27$ but hematuria does not usually occur $^{15}$. The mechanism of onset of thrombosis is not yet defined and it is considered more of a complication than the cause of nephrotic syndrome $e^{9,27}$ and, in these situations, hypercoagulable is 
evident ${ }^{9,26,27}$. Although there are peculiarities of the venous system of small animals, the veins of the abdomen are of simpler handling than the arteries and, experimentally, murine models are used to evaluate the thrombogenic factors performing the ligature of the inferior vena cava, when progression of thrombus to the renal veins may occur ${ }^{7,8,10}$. In the obstructions of renal vein, lesions in great part of parenchyma are expected, but areas with preserved architecture may remain. The medullary portion may present loss of tubules replaced by connective tissue and macrophages; in the adjacent cortical region, proximal tubule atrophy as well as dilation of Bowman's capsule, followed by a period of loss of water and electrolytes was observed ${ }^{25}$. We found an extensive inflammatory process, scattered polymorphonuclear and infiltrates of these cells (Figure 4).

Threefoot et al. ${ }^{11}$, studying models of corrosion of tissues after injection of methacrylate in the renal vessels of female rats, showed the development of collateral vessels on the kidney from the third day after ligation of the renal vein, especially when it is close to the inferior vena cava. A higher development of such circulation occurred at the end of the first week and remained stable until the end of the experiment, on the twentieth day. These studies considered the possibility of secondary thrombosis of renal artery in some animals, since they have failed to demonstrate the filling of this arterial branch. In the study here performed, the ligation of the renal vein was always near the right hilum and we have found no collateral circulation in any animals of group three. Although the right kidney presented both macroscopic and microscopic appearance of severe degeneration, there were signs of arterial blood perfusion in all animals of this group a week after the experiment, as it can be observed in Figure 1 (II).

The authors above ${ }^{11}$ found histological changes in the contralateral kidney in 30 to 65 percent of the animals when unilateral ligature was performed, mainly when the right kidney was considered, with signs of infarction, hemorrhage, congestion and degeneration of the kidney tubules. When the ligature of left renal vein was evaluated, they found congestion, tubular degeneration and dilatation in 30 percent of the animals. The expected result in our study would be congestion and dilation of tubules, implying some degree of vicarious activity of the left kidney, which was always preserved in the experiment, but we have found no histological differences between the right kidney, removed in the first operation, which is considered a normal control, and the left kidney removed one week after the experiment. Erythrocytes were detectable in the tubules of the left kidney, removed in the second operation, but we could not detect hematuria through the method used in this study.
A major edema of the kidney a few hours after vein ligation is expected with better survival rates than after bilateral ligation of the renal veins, which is related to where the ligation is performed, being more successful when it is made next to the inferior vena cava, especially on the left, and also when the right and left veins are occluded in different days, not at the same time. Studies in dogs one to six weeks after the ligatures showed significant collateral circulation and only a transient alteration of excretion of electrolytes and mainly proteins ${ }^{11}$. Proteinuria found by Threefoot et al. ${ }^{11}$ showed a peak on the second day after vein ligation (four times above baseline values), becoming close to normal rates by the fifth day, reaching twice the baseline on the eighth day, remaining almost normal after this period, possibly due to the congestion and increase of venous pressure. Likewise, the absence of collateral circulation makes stasis in the venous system to be followed by venous thrombosis and progression of functional alterations. These studies showed a survival rate for two weeks of eighty percent of the animals with ligation of one of the renal veins and twenty-seven percent when bilateral ligation of the veins was performed, especially when they were occluded next to the inferior vena cava ${ }^{11}$.

In the experiment performed here, the attempts of simultaneous ligation of the renal veins with preservation of the kidneys, or ligation of the renal vein with contralateral nephrectomy, were incompatible with the survival of animals, tactics that were tried during the pilot study. The renal function of rats changed early when unilateral nephrectomy was performed and more intensely when the right renal vein was occluded and this kidney was preserved only with the arterial blood supply.

\section{Conclusions}

The right nephrectomy and ligation of the right renal vein with kidney preservation were responsible for early functional and histological alterations of the kidneys, especially in the second model. The left kidney preserved in both models failed to adequately maintain renal function.

\section{References}

1. Imaoka T, Kusuhara H, Adachi-Akahane S, Hasegawa M, Morita N, Endou H, Sugiyama Y. The renal-specific transporter mediates facilitative transport of organic anions at the brush border membrane of mouse renal tubules. J Am Soc Nephrol. 2004;15:2012-22. doi: 10.1097/01.ASN.0000135049.20420.E5.

2. López-Novoa JM, Rodríguez-Peña AB, Ortiz A, Martínez-Salgado C, Hernández FJL. Etiopathology of chronic tubular, glomerular and renovascular nephropathies. Clinical implications. J Translational Med. 2011;9:13-38. PMID: 21251296 
3. Miyazaki H, Anzai N, Ekaratanawong S, Sakata T, Shin HJ, Jutabha P, Hirata T, He X, Nonoguchi H, Tomita K, Kanai Y, Endou H. Modulation of renal apical organic anion transporter 4 function by two pdz domain-containing proteins. J Am Soc Nephrol. 2005;16:3498-506. doi: 10.1681/ASN.2005030306.

4. Sweet DH, Chan LMS, Walden R, Xiao-Ping Y, Miller DS, Pritchard JB. Organic anion transporter 3 (Slc22a8) is a dicarboxylate exchanger indirectly coupled to the $\mathrm{Na}^{+}$gradient. Am J Physiol Renal Physiol. 2003;284:763-9. PMID: 12488248.

5. Fazan Jr R, Dias da Silva VJ, Salgado HC. Modelos de hipertensão arterial. Rev Bras Hipertens. 2001;8:19-29.

6. Motojima M, Hosokawa A, Yamato H, Muraki T, Yoshioka T. Uraemic toxins induce proximal tubular injury via organic anion transporter 1-mediated uptake. Br J Pharmacol. 2002;135:555-63. doi: 10.5935/0101-2800.20140042.

7. Brill A, Fuchs TA, Savchenko AS, Thomas GM, Martinod K, DeMeyer SF, Bhandari AA, Wagner DD. Neutrophil extracellular traps promote deep vein thrombosis in mice. J Thromb Haemost. 2012;10:136-44. doi: 10.1111/j.1538-7836.2011.04544.x.

8. von Brühl M-L, Stark K, Steinhart A, Chandraratne S, Konrad I, Lorenz M, Khandoga A, Tirniceriu A, Coletti R, Köllnberger M, Byrne RA, Laitinen I, Walch A, Brill A, Pfeiler S Munukyan D, Braun S, Lange P, Riegger J, Ware J, Eckart A, Haidari S Rudelius M Schulz C, Echtler K, Brinkmann V, Schwaiger M, Preissner KT, Wagner DD, Mackman N, Engelmann B, Massberg S. Monocytes, neutrophils, and platelets cooperate to initiate and propagate venous thrombosis in mice in vivo. J Exp Med. 2012;209:819-35. doi: 10.1084/jem.20112322.

9. Chugh KS, Malikt N, Uberoi HS, Gupta VK, Aggarwalt ML, Singhal $\mathrm{PC}$, Suri S, Jain SK. Renal vein thrombosis in nephrotic syndrome-a prospective study and review. Postgrad Med J. 1981;57:566-70. doi: 10.1136/pgmj.57.671.566.

10. Diaz JA, Obi AT, Myers Jr DD, Wrobleski SK, Henke PK, Mackman N, Wakefield TW. Critical review of mouse models of venous thrombosis. Arterioscler Thromb Vasc Biol. 2012;32(3):556-62. doi: 10.1161/ATVBAHA.111.244608.

11. Threefoot SA, Cabrera-Gil C, Pearson Jr JE. Collateral circulation, renal function and histology after experimental obstructionof renal veins. Chest. 1970;58:249-60. PMID: 5458692.

12. Hassan AZ, Kadima KB, Remi-adewumi BD, Awasum CA, Abubakar MT. Animal models in surgical training: choise and ethics. Nigerian J Surg Res. 2005;7:260-7. doi: 10.4314/njsr.v7i3.12292.

13. Silva AR, Kriguer Jr RJ, Serigiolle LC, Gomes HMP, Rodrigues $\mathrm{DAB}$, Leme PLS. Increase in spleen volume of rats on experimental model of pre-hepatic portal hypertension. Arq Bras Cir Dig. 2013;26(3): 206-12. doi: 10.1590/S0102-67202013000300010.

14. Andreollo NA, Santos EF, Araújo MR, Lopes LR. Idade dos ratos versus idade humana: qual é a relação? Arq Bras Cir Dig. 2012;25:49-51. doi: 10.1590/S010267202012000100011.

15. Ning-Sheng L, Joung-Liang L. Renal vein thrombosis in Chinese patients with systemic lupus erythematosus. Ann Rheumatic Dis. 1997;56:562-4. doi: 10.1191/0961203305lu2058oa.

16. Alves MAR. Diagnóstico de doença renal crônica: avaliação de proteinúria e sedimento urinário. J Bras Nefrol. 2004;26 (3, suppl. 1):6-8.

17. Jafar TH, Stark PC, Schmid CH, Landa M, Maschio G, de Jong PE, Levey AS. AIPRD Study Group Progression of chronic kidney disease: the role of blood pressure control, proteinuria, and angiotensin-converting enzyme inhibition: a patientlevel metaanalysis. Ann Intern Med. 2003;139(4):244-52. doi: 10.7326/0003-4819-139-4-200308190-00006.
18. Anzai N, Jutabha P, Enomoto A, Yokoyama H, Nonoguchi H, Hirata T, Endou H. Functional characterization of rat Organic Anion Transporter 5 (Slc22a19) at the apical membrane of renal proximal tubules. J Pharmacol Exp Therap. 2005;315(2):534-44. doi: 10.1124/jpet.105.088583.

19. Hagos Y, Stein D, Ugele B, Burckhardt G, Bahn A. Human renal organic anion transporter 4 operates as an asymmetric urate transporter. J Am Soc Nephrol. 2007;18(2):430-9. doi: 10.1681/ ASN.2006040415.

20. Sauvant C, Hesse D, Holzinger H, Evans KK, Dantzler WH, Gekle M. Action of EGF and PGE2 on basolateral organic anion uptake in rabbit proximal renal tubules and hOAT1 expressed in human kidney epithelial cells. Am J Physiol Renal Physiol. 2004;286:77483. PMID: 14644751.

21. Ueo H, Motohashi $\mathrm{H}$, Katsura T, Inui $\mathrm{K} . \mathrm{Cl}^{-}$-dependent upregulation of human organic anion transporters: different effects on transport kinetics between hOAT1 and hOAT3. Am J Physiol Renal Physiol. 2007;293:391-7. PMID: 17429031.

22. Soares BLF, Freitas MAL, Montero EFS, Pitta GBB, Miranda Jr F. Alprostadil attenuates inflammatory aspects and leucocytes adhesion on renal ischemia and reperfusion injury in rats. Acta Cir Bras. 2014;29 (suppl. 2):55-60. doi: 10.1590/S0102-8650201400140011.

23. Wang Z-s, Liu X-h, Wang M, Jiang G-j, Qiu T, Chen Z-y, Wang L. Metformin attenuated the inflammation after renal ischemia/ reperfusion and suppressed apoptosis of renal tubular epithelial cell in rats. Acta Cir Bras. 2015;30:617-23. doi: 10.1590/S0102$865020150090000006 \mathrm{IPhD}$.

24. Cerqueira N F, Hussni C A, Yoshida W B, Padovani C R. Systemic evaluation on ischemia and reperfusion injury of splanchnic organs in rats. Acta Cir Bras. 2009;24(4):290-5. doi: 10.1590/S010286502009000400008

25. Evans DJ, Silverman M, Bowley NB. Congenital hypertension due to unilateral renal vein thrombosis. Arch Dis Child. 1981;56:306-8. doi: 10.1136/adc.56.4.306.

26. Subbiah V, Parimi P. Elevated maternal lipoprotein (a) and neonatal renal vein thrombosis: a case report. J Med Case Rep. 2008;2:106-9. doi: 10.1186/1752-1947-2-106.

27. 19. O'Brien AA, O'Donnell JP, Keogh JAB. Renal vein thrombosis with recurrent pulmonary emboli in the nephrotic syndrome: use of the Greenfield filter. Postgrad Med J. 1986;62:223-5. PMID: 3714611 .

\section{Correspondence:}

Pedro Luiz Squilacci Leme

Avenida das Nações Unidas, 561/52

09726-110 São Bernardo do Campo - SP Brasil

Tel.: (55 11)4330-1977 / 99133-9057

gorableme@uol.com.br

\section{Received: Aug 13, 2015}

Review: Oct 10, 2015

Accepted: Nov 15, 2015

Conflict of interest: none

Financial source: none

${ }^{1}$ Research performed at Advanced Surgical Skills Laboratory, Universidade Nove de Julho (UNINOVE), Sao Paulo-SP, Brazil. 